\title{
A Comparative Study of the Frequency of Post-Traumatic Stress Disorder in Women Undergoing Normal Vaginal Delivery and Cesarean Section
}

\author{
Prof. Dr. Seyed Saeid Zamanieh Shahri, MD*, and Prof. Dr. Sonia Sayyedalhosseini, MD* \\ Faculty Members in California Northstate University, CNSU-University Professors in Losrios Community College District, USA
}

*Corresponding authors: Prof. Dr. Seyed Saeid Zamanieh Shahri, MD, Faculty Member in California Northstate University, CNSU-University Professor in Losrios Community College District, USA, Tel: (916)724-9485; E-mails: saeid.zamanieh@cnsu.edu, zamanis@flc.losrios.edu

Prof. Dr. Sonia Sayyedalhosseini, MD, Faculty Member in California Northstate University, CNSU-University Professor in Losrios Community College District, USA, E-mails: sonia.sayyedalhosseini@cnsu.edu, sayyeds@flc.losrios.edu

Received: 07 Dec, 2020 | Accepted: 02 Jan, 2021 | Published: 08 Jan, 2021

Citation: Shahri SSZ, Sayyedalhosseini S (2021) A Comparative Study of the Frequency of Post-Traumatic Stress Disorder in Women Undergoing Normal Vaginal Delivery and Cesarean Section. Gynecol Women's Health Res 3(1): dx.doi.org/10.16966/2689-3096.117

Copyright: (C 2021 Shahri SSZ, et al. This is an open-access article distributed under the terms of the Creative Commons Attribution License, which permits unrestricted use, distribution, and reproduction in any medium, provided the original author and source are credited.

\begin{abstract}
Introduction and Objective: Childbirth may be a stressful event for some women and trauma that some of them experienced during childbirth can cause Post-Traumatic Stress Disorder (PTSD). The aim of this study was to compare the frequency of PTSD among women with Normal Vaginal Delivery (NVD) and cesarean section (C-Section).

Materials and Methods: Postpartum women were evaluated for post-traumatic stress disorder during the delivery and the first 12 weeks after delivery. Demographic characteristics and type of delivery were assessed. The STP (Spanning Tree Protocol) interview questionnaire was completed for them and the obtained data were statistically compared between the two groups of NVD and cesarean section.

Results: 1240 postpartum women participated in this study. The frequency of post-traumatic stress was higher in women with NVD than the women with cesarean section. There was a significant relationship between the occurrence of post-traumatic stress disorder with age and maternal occupation ( $P=001, P=21 \%$ ). But there was not a significant relationship between the occurrences of PTSD with level of education.

Conclusion: In this study, the frequency of PTSD was higher in the in women with NVD than in the C-section group. This is a health problem that needs attention to reduce the risk of trauma in NVD and offering more pain-free methods of NVD and psychiatric counseling and teaching mothers
\end{abstract} about the benefits of NVD to decrease elective C-section level. All those consideration may reduce the risk of PTSD in these individuals.

Keywords: Post-traumatic stress disorder; Normal delivery; Cesarean section

\section{Introduction}

Pregnancy and childbirth are unique situations that make anxiety for women [1]. Fear of childbirth, the birth of an abnormal baby, loss of attractiveness to the spouse, and a dual feeling of caring for the newborn make many mothers anxious, and the postpartum period, especially the first 6 weeks after it, becomes an important vulnerable period for mental disorders [2].

\section{Natural childbirth}

Labor is the process that leads to childbirth. It begins with the onset of regular uterine contractions and ends with delivery of the newborn and expulsion of the placenta. Pregnancy and birth are physiological processes, and thus, labor and delivery should be considered normal for most women. The mechanism of labor is changes in pelvic floor. Many adaptive changes are required for pregnancy and for labor and delivery. According to Nygaard I, vaginal delivery is a traumatic event [3].

\section{Cesarean section}

Of definitions, cesarean delivery defines the birth of a fetus via laparotomy and then hysterotomy. This definition is not applied to removal of the fetus from the abdominal cavity in the case of uterine rupture or with abdominal pregnancy [3].

The anterior surface of the uterus is opened longitudinally along its midline. This is best accomplished by making an incision a few centimeters long with a scalpel, and then rapidly enlarging it with the scissors to 16 or 18 centimeters. The membranes are then ruptured, the child is seized by one foot and rapidly extracted-Williams JW [3].

Bad childbirth experiences, unexpected medical interventions, severe pain, or fear of death can sometimes cause severe fear and anxiety in mothers, which can lead to post-traumatic stress disorder after childbirth. This less commonly diagnosed disorder may occur alone or with depression [4]. The experience of trauma during childbirth can have a negative impact on the mother's mental 
functioning and postnatal adjustment [5]. According to the American Psychiatric Association, a sudden traumatic event can disrupt a person's performance by creating a sense of helplessness, panic and can be accompanied by periods of community avoidance $[1,6]$. The etiology of traumatic postpartum anxiety includes genetic, hereditary factors, environmental factors, psychological factors, social factors and biological factors [7].

Risk factors for PTSD after delivery are mostly the same as for PTSD after any other trauma, with some specificity related to the event, but not much is known about specific risk factors for PTSD after regular vaginal delivery. These risk factors might be pre-traumatic, peritraumatic and posttraumatic [8].

The first child's birth and the choice of delivery type are considered as the most important events for the primiparous women. The Normal Vaginal Delivery (NVD) as a normal physiological process has many benefits for both the mother and the child [9].

Cesarean section, in comparison with NVD, has many dangerous consequences for the mother and the child [10].

Today, cesarean section is the first option for primiparous women in most countries especially in Iran [11].

In recent years, the rate of cesarean section is $48 \%$ in Iran that has increased to $87 \%$ in some private hospital [12], most of which are without medical indication [13]. The causes for the high rate of caesarian section have been studied. Sahlin M, et al. [14] mentioned that negative child birth experience is one of the contributing factors on women's tendency for choosing cesarean section. Evidence showed that $10-20 \%$ of all women have negative birth experiences [15].

Therefore, in this study, we aimed to compare the frequency of posttraumatic stress disorder after NVD and cesarean section, to identify the factors affecting it, perhaps a step to better control the mental health of women after childbirth and therefore a healthier family harvest.

\section{Reacting to stressful experiences}

Acute Stress Disorder is a caused by trauma (traumatic stress) and lasts at least 3 days. The DSM-V manual states that stressful events which do not include severe and traumatic components do not lead to Acute Stress Disorder; Adjustment Disorder may be an appropriate diagnosis. Acute Stress Disorder develops after exposure to one or more traumatic events, e.g., exposure to war (both civilians and military personnel), rape or sexual violence, physical attack, mugging, childhood physical or sexual violence, kidnapping or being taken hostage, terrorist attacks, torture, nature disasters and severe accidents. Many other causes of trauma are possible [1].

\section{Post-traumatic stress disorder}

In 2013, the American Psychiatric Association revised the PTSD diagnostic criteria in the fifth edition of its Diagnostic and Statistical Manual of Mental Disorders (DSM-V). PTSD is included in a new category in DSM-V, Trauma- and Stressor-Related Disorders. All of the conditions included in this classification require exposure to a traumatic or stressful event as a diagnostic criterion. Note that DSM-V introduced a preschool subtype of PTSD for children ages six years and younger. The criteria below are specific to adults, adolescents, and children older than six years. All of the criteria are required for the diagnosis of PTSD [2]. The following text summarizes the diagnostic criteria:

Criterion A: Stressor (one required) The person was exposed to: death, threatened death, actual or threatened serious injury, or actual or threatened sexual violence, in the following way(s): direct exposure, witnessing the trauma, learning that a relative or close friend was exposed to a trauma, indirect exposure to aversive details of the trauma, usually in the course of professional duties (e.g., first responders, medics).

Criterion B: Intrusion symptoms (one required). The traumatic event is persistently re-experienced in the following way(s): unwanted upsetting memories, nightmares, flashbacks, emotional distress after exposure to traumatic reminders, physical reactivity after exposure to traumatic reminders.

Criterion C: Avoidance (one required). Avoidance of traumarelated stimuli after the trauma, in the following way(s): traumarelated thoughts or feelings, trauma-related external reminders.

Criterion D: Negative alterations in cognitions and mood (two required). Negative thoughts or feelings that began or worsened after the trauma, in the following way(s): inability to recall key features of the trauma, overly negative thoughts and assumptions about oneself or the world, exaggerated blame of self or others for causing the trauma, negative effect, decreased interest in activities, feeling isolated, difficulty experiencing positive affect.

Criterion E: Alterations in arousal and reactivity Trauma-related arousal and reactivity that began or worsened after the trauma, in the following way(s): irritability or aggression, risky or destructive behavior, hypervigilance, heightened startle reaction, difficulty concentrating, difficulty sleeping.

Criterion F: Duration (required): symptoms last for more than 1 month.

Criterion G: Functional significance (required): symptoms create distress or functional impairment (e.g., social, occupational).

Criterion H: Exclusion (required): symptoms are not due to medication, substance use, or other illness.

Two specifications:

- Dissociative Specification: In addition to meeting criteria for diagnosis, an individual experiences high levels of either of the following in reaction to trauma-related stimuli: Depersonalization Experience of being an outside observer of or detached from oneself (e.g., feeling as if "this is not happening to me" or one were in a dream). Derealization - Experience of unreality, distance, or distortion (e.g., "things are not real").

- Delayed Specification. Full diagnostic criteria are not met until at least six months after the trauma(s), although onset of symptoms may occur immediately [2].

The overall aim of this study was to compare the frequency of PTSD in women following NVD and C-section.

\section{Materials and Methods}

Type of this study was descriptive-analytical. Research community was all women with a history of one or more delivery referred to all hospitals affiliated to the Charity Hospitals of Mashhad University. The inclusion criteria included satisfaction to participate in the research and having a minimum literacy of reading and writing. Exclusion criteria consisted of history of severe stress in the last 6 months, history of diagnosis of previous PTSD, history of hospitalization in a psychiatric hospital, history of obvious psychiatric disorders such as epilepsy or brain disorder and history of infertility. 
Table of variables were performed. Dependent and independent variables, Correlation Coefficient, Pearson's Coefficient, Degree of freedom, Observed value and expected value, t-test and Chi-square test were calculated.

Chi Square Test: there are two types of chi-square tests. Both use the chi-square statistic and distribution for different purposes:

- A chi-square goodness of fit test determines if sample data matches a population.

- A chi-square test for independence that compares two variables in a contingency table to see if they are related. In a more general sense, it tests to see whether distributions of categorical variables differ from each another. This is the purpose of using this method in our study.

- A very small chi square test statistic means that your observed data fits your expected data extremely well. In other words, there is a relationship.

- A very large chi square test statistic means that the data does not fit very well. In other words, there isn't a relationship.

$$
x_{c}^{2}=\sum \frac{\left(\mathrm{O}_{i}-\mathrm{E}_{i}\right)^{2}}{E_{i}}
$$

The subscript " $c$ " is the degrees of freedom. "O" is your observed value and $\mathrm{E}$ is your expected value. The summation symbol means that you'll have to perform a calculation for every single data item in your data set. As you can probably imagine, the calculations can get very, very, lengthy and tedious. Instead, you'll probably want to use technology: either Chi Square Test in SPSS or Chi Square P-Value in Excel. That in our study Chi Square Test in SPSS was performed [16].

The sample size was calculated according to the articles by Ryding EL, et al. $[17,18]$ who reported acute stress in two groups of NVD and cesarean section $3.9 \%$ and $7.6 \%$, respectively. So, we have decided to consider at least 620 women in each group of NVD and cesarean section by the confidence interval of $95 \%$ and Power of Test $80 \%$ with the following formula.

$$
\begin{aligned}
& n=\frac{\left(p_{1}\left(1-p_{1}\right)+p_{2}\left(1-p_{2}\right)\right)\left(z_{1-\frac{\alpha}{2}}+z_{1-\beta}\right)^{2}}{\left(p_{1}-p_{2}\right)^{2}} \\
& n=\frac{\left(p_{1}\left(1-p_{1}\right)+p_{2}\left(1-p_{2}\right)\right)(1.96+0.84)^{2}}{\left(p_{1}-p_{2}\right)^{2}}
\end{aligned}
$$

Methods and tools of data collection in this study, included:

a. Pre-prepared questionnaire of personal characteristics including age, education level and occupation to any job.

b. Structured Interview with Stress Outcome Disorder (SIP).

The collected data analyzed by using statistical tests (t-test, Chi-square, Fisher) and SPSS computer software version 18. The significance level of the tests was less than 0.05 .

\section{Research Results}

The age distribution of the population we studied was as shown in the table 1 .

Distribution of education level in our study population was as shown in the table 2 .

The occupation status in our study population was as shown in the table 3 and figure 1.
Table 1: The age distribution of the population.

\begin{tabular}{|l|c|}
\hline \multicolumn{2}{|c|}{ Age } \\
\hline Sample numbers & 1240 \\
\hline The average & $33 / 35$ \\
\hline The standard deviation & $8 / 798$ \\
\hline Minimum & 20 \\
\hline Maximum & 54 \\
\hline
\end{tabular}

The Group Statistics of PTSD frequency based on delivery type in our study group was as shown in the table 4 and PTSD frequency based on delivery type in study group was as shown in the table 5 .

According to the frequency table 4 and 5 , it was observed that the highest frequency of PTSD was related to women who had NVD, 486 women in compare with C-section. This comparison can be seen much apparent in the columnar chart of figure 2.

Table 6 showed comparison of the frequency of PTSD in NVD and C-section based on mother's occupation.

Comparison of the frequency of PTSD in NVD and C-section based on maternal education was as shown in table 7 .

According to the education level the highest frequency was related to non-graduated. But after the calculated P (sig.) value of Fisher's exact test was concluded by variance table 8 , the average of PTSD in the three groups of education level was equal and there was no statistically significant difference in occurrence of PTSD base on education level and type of delivery.

By using the information in table 1 , the linear regression model and the correlation coefficient of 0.386 between PTSD and maternal age was equal to the calculations and studies with $\mathrm{p}$ value of 0.001 . That was, at the error level of one percent. The positive sign of the correlation coefficient means that there is a direct relationship between PTSD and maternal age with increasing maternal age, the amount of PTSD also increases. Given this significant relationship, we used the linear regression model. Therefore, a model that can be fitted to the relationship between PTSD and maternal age according to the collected data was;

$$
P T S D=+6.8(0.381) \times \text { Age }
$$

\section{Discussion, Results and Conclusion}

Pregnancy and childbirth are unique cases of anxiety for women. Fear of childbirth, the birth of an abnormal baby, the loss of attractiveness for the spouse and the dual feeling of caring for the newborn make many mothers anxious. The postpartum period, especially the first 6 weeks after that, is an important vulnerable period for mental disorders. Experience of unexpected medical interventions, severe pain or fear of death during childbirth, can cause severe anxiety in mothers, which can lead to PTSD after childbirth. This disorder is less commonly diagnosed. It may occur alone or with depression [19]. The experience of postpartum trauma can have a negative impact on the mother's psychological functioning and adaptation in the postpartum period. In the etiology of postpartum anxiety includes genetic, hereditary, environmental, psychological, social and biological factors [20]. In this study, we compared the prevalence of PTSD after NVD and C-section to identify the factors affecting it. Identifying the issues help to have better control over the mental health of women after childbirth and have a healthier family [6]. 
Table 2: The education level distribution.

\begin{tabular}{|l|l|c|c|c|c|}
\hline \multicolumn{3}{|l|}{ Education level } \\
\hline \multirow{5}{*}{ Distribution value } & & Frequency & Percentage & Valid percentage & Cumulative frequency percentage \\
\hline \multirow{3}{*}{} & College or higher & 20 & $1 / 6$ & $1 / 6$ & $38 / 7$ \\
\cline { 2 - 6 } & Graduated & 480 & $38 / 7$ & $59 / 7$ & $1 / 6$ \\
\cline { 2 - 6 } & Non-graduated & 740 & $59 / 7$ & $100 / 3$ \\
\cline { 2 - 6 } & Total numbers & 1240 & $100 / 0$ & 100 \\
\hline
\end{tabular}

Table 3: Job distribution in our study population.

\begin{tabular}{|l|l|c|c|c|c|}
\hline \multicolumn{5}{|l|}{ Having job } \\
\hline \multirow{3}{*}{ Distribution value } & No job & Frequency & Percentage & Valid percentage & Cumulative frequency percentage \\
\cline { 2 - 6 } & Having job & 248 & $22 / 9$ & $22 / 9$ & $22 / 9$ \\
\cline { 2 - 6 } & Total numbers & 956 & $77 / 1$ & 1 & $100 / 0$ \\
\hline
\end{tabular}

Table 4: Group Statistics of PTSD frequency based on delivery type in study group.

\begin{tabular}{|l|c|c|c|c|c|}
\hline \multicolumn{4}{|c|}{ Group Statistics } \\
\hline \multirow{3}{*}{ PTSD } & Type of delivery & Number & Frequency & Standard deviation & Average standard error \\
\cline { 2 - 6 } & NVD & 620 & $21 / 30$ & $8 / 055$ & $9 / 049$ \\
\hline
\end{tabular}

Table 5: PTSD frequency based on delivery type in study group.

\begin{tabular}{|l|c|c|c|c|}
\hline \multicolumn{4}{|c|}{ Number } \\
\hline \multicolumn{2}{|c|}{} & \multicolumn{2}{c|}{ Type of delivery } & Total \\
\cline { 3 - 5 } & & NVD & C-section & \\
\hline \multirow{3}{*}{ PTSD } & - & 134 & 298 & 432 \\
\cline { 2 - 5 } & + & 486 & 322 & 808 \\
\hline Total & & 620 & 620 & 1240 \\
\hline
\end{tabular}

In this study, 1240 women were studied. The mean age of the women was 33.35 years with a standard deviation of 8.798 years. The lowest age in this study group was 20 years old and the highest was 45 years old.

Among the subjects in the study, 620 had NVD and 620 had a C-section. In patients with NVD, the mean of PTSD was 21.3 with a standard deviation of 8.05 and the standard mean error was 1.324 . In patients with C-section, the mean PTSD was 16.84 with a standard deviation of 9.04 with a standard mean error of 1.810. The mean PTSD was lower in women with C-section than in those with a history of NVD. There was a statistically significant difference between the two groups of NVD and C-section in terms of attitude towards labor pain, so that the average negative attitude towards labor pain in NVD group was higher than $\mathrm{C}$-section group. The mean and standard deviation of pregnant women's desire for C-section was higher than NVD, which was statistically significant and there was a significant inverse correlation between perceived pain intensity and desire for NVD. It may be due to the same attitude of women towards the pain of NVD, and therefore painless childbirth may be the solution of this problem [21].
In our study, the prevalence of PTSD based on the type of delivery and mother's occupation was as follows:

$$
\begin{aligned}
& \frac{P T S D \text { Positive in housewives with NVD }}{\text { Total housewives with NVD }}=\frac{132}{143} \\
& \frac{P T S D \text { Positive in housewives with } C-\text { Section }}{\text { Total housewives } C-\text { Section }}=\frac{91}{41} \\
& \frac{P T S D \text { Positive in women having a job with NVD }}{\text { Total women having a job with NVD }}=\frac{363}{477} \\
& \frac{P T S D \text { Positive in women having a job with } C-\text { Section }}{\text { Total women having a job with } C-\text { Section }}=\frac{254}{479}
\end{aligned}
$$

P-value was equal to $029 \%$ that, at the error level of $\mathrm{P}$, the correlation coefficient between PTSD and maternal age was $384 \%$ and the percentage of this correlation coefficient was significant. The positive sign of the correlation coefficient meant that there was a direct relationship between PTSD and maternal age; that is, with increasing maternal age, the rate of PTSD also increased. Considering that there was a significant relationship between PTSD and maternal age, we tended to express the mathematical model of this relationship. For this purpose, we used the linear regression model. The information that this model can provide us was very useful. For example, for a one-year increase in maternal age, the rate of PTSD increased by $381 \%$ [21].

The mean of PTSD was the same in the three groups of education and was not statistically significant difference among these 3 groups. There was no correlation between them. 
Table 6: Comparison of PTSD in two types of delivery based on having job.

\begin{tabular}{|c|c|c|c|c|c|}
\hline \multirow{2}{*}{ Having job } & & & \multicolumn{2}{|c|}{ Type of delivery } & \multirow[t]{2}{*}{ Total } \\
\hline & & & NVD & C-section & \\
\hline \multirow{3}{*}{ No job } & \multirow{2}{*}{ PTSD } & - & 11 & 50 & 61 \\
\hline & & + & 132 & 91 & 223 \\
\hline & \multicolumn{2}{|l|}{ Total } & 143 & 141 & 284 \\
\hline \multirow{3}{*}{ Having job } & \multirow{2}{*}{ PTSD } & - & 114 & 225 & 339 \\
\hline & & + & 363 & 254 & 617 \\
\hline & \multicolumn{2}{|l|}{ Total } & 477 & 479 & 956 \\
\hline
\end{tabular}

Table 7: Comparison of PTSD in two types of delivery based on having job.

\begin{tabular}{|c|c|c|c|c|c|}
\hline \multirow{2}{*}{$\begin{array}{l}\text { Education } \\
\text { level }\end{array}$} & & & \multicolumn{2}{|c|}{ Type of delivery } & \multirow[t]{2}{*}{ Total } \\
\hline & & & NVD & C-section & \\
\hline \multirow{2}{*}{$\begin{array}{l}\text { College or } \\
\text { higher }\end{array}$} & PTSD & + & 20 & & 20 \\
\hline & \multicolumn{2}{|l|}{ Total } & 20 & & 20 \\
\hline \multirow{3}{*}{ Graduated } & \multirow{2}{*}{ PTSD } & - & 40 & 80 & 120 \\
\hline & & + & 220 & 140 & 360 \\
\hline & \multicolumn{2}{|l|}{ Total } & 260 & 220 & 480 \\
\hline \multirow{3}{*}{$\begin{array}{l}\text { Non- } \\
\text { graduated }\end{array}$} & \multirow{2}{*}{ PTSD } & - & 100 & 180 & 280 \\
\hline & & + & 240 & 220 & 460 \\
\hline & \multicolumn{2}{|l|}{ Total } & 340 & 400 & 740 \\
\hline
\end{tabular}

Table 8: Pearson correlation coefficient table for two variables of PTSD and maternal education level.

\begin{tabular}{|l|l|c|c|}
\hline \multicolumn{4}{|c|}{ Efficiency } \\
\hline \multirow{4}{*}{ PTSD } & Pearson correlation & 1 & $-0 / 057$ \\
\cline { 2 - 4 } & P-value (2-tailed) & & $0 / 660$ \\
\cline { 2 - 4 } & Number & 620 & 620 \\
\hline \multirow{3}{*}{ Education level } & Pearson correlation & $-0 / 057$ & 1 \\
\cline { 2 - 4 } & P-value (2-tailed) & $0 / 660$ & \\
\cline { 2 - 5 } & Number & 620 & 620 \\
\hline
\end{tabular}

According to the study in medical school of Serbia by experts on 2016 which was the first in Southeast Europe to include only NVD primiparous women and the findings showed that NVD is not a risk factor for PTSD. The obstetrical complications as an unplanned change significantly increase the likelihood of PTSD. This article supported our findings regarding to the reasons of preferring less NVD in Iran, not because of the nature of NVD but because of the unskillful midwifery students in charity hospitals that lead to obstetrical complications [8].

In our study, the incidence of PTSD in women with NVD was higher than C-section. This is the first research to find such result. So, it could be clarified by the following explanations.

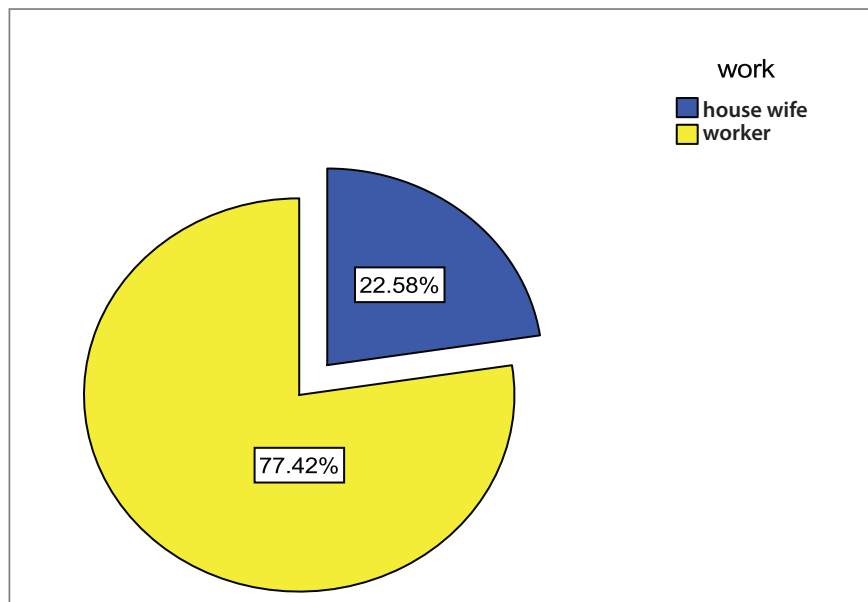

Figure 1: Job distribution.

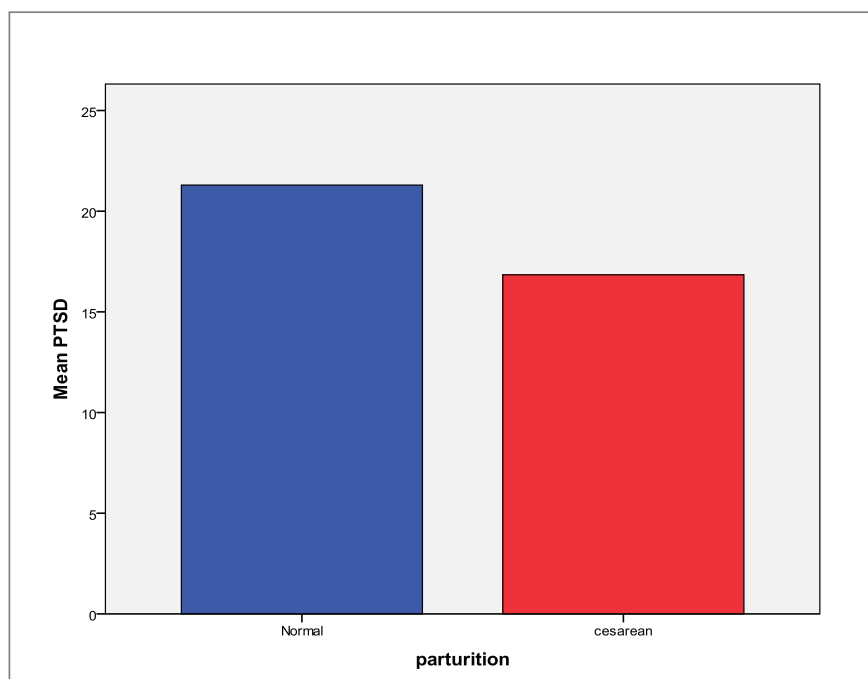

Figure 2: PTSD frequency based on delivery type in study group.

- In Iranian society, due to the fact that C-section could be performed completely elective and voluntarily at the request of pregnant women, in addition to emergencies, many pregnant women ask their gynecologist to do so. Some of the reasons of choosing elective C-Section are as follows: women who had a history of traumatic NVD or have friends and family which had such bad experiences, they afraid of similar accidents during NVD, so they chose to have C-Section instead. Some of these traumatic events include severe vaginal bleeding, prolonged labor or a failure to progress (obstructed labor, also known as dystocia), fetal distress, cord prolapse, uterine rupture or an elevated risk thereof, hypertension in the mother or baby after amniotic rupture, tachycardia in the mother or baby after amniotic rupture (the waters breaking), needing intervention during labor such as an assisted delivery (using forceps or ventouse) or complications of episiotomy, fear of long lasting labor pains especially with insufficient effacement and failure to progress, unpleasant and disgusting feeling that the pregnant women endure in repeatedly vaginal examinations which are necessary to assess labor progression. 
- Due to the fact that pregnant women referring to charitable hospitals affiliated to the University of Mashhad were examined in our study and that these hospitals are also considered teaching hospitals, NVD is performed by midwifery students and not the gynecologist. So, pregnant women had worried and felt unsecure in the absence of gynecologist while in cesarean section, the mother is assured that during the whole process gynecologist is present. Most of C-Sections in our study were uncomplicated, normal across from side-to-side (horizontal) incision that extended across the pubic hairline. It's used most often, because it heals well and there is less bleeding.

In our study, the incidence of PTSD in women with NVD was higher than C-section. This is important culturally, healthily and socially [22]. One of the possible reasons for this is the lack of knowledge of women about new methods of painless NVD, which will decrease the occurrence of anxiety before and during childbirth in women. Excessive publicity about C-section, which affects mothers' attitudes, can be another factor [23]. The perception of labor pain can affect the desire and preference of the type of labor of pregnant women, so that increasing the negative perception about the pain of normal labor, significantly reduces the tendency to normal labor. Improve midwifery student's skills to prevent complications during NVD. Educating pregnant women can reduce the fear and anxiety of misconceptions about the pain of NVD and encourage them to have normal childbirth [24]. However, today, C-section is perceived as an escape from labor pain, and the false assumption that $\mathrm{C}$-section is painless, safer, and healthier than vaginal delivery has become prevalent among women. In fact, more than half of the women voluntarily choose C-section as the preferred mode of delivery [25]. The result of Khamehchian M, et al. [26] studies showed that hearing bitter experiences of other women regarding NVD process was the main source of concern in the primiparous women in her study in Kashan, a city in the center of Iran. A significant step in controlling the rising cesarean birth rate in developing countries is providing better information to pregnant women and their partners during the antenatal period about modes of delivery, their indications, advantages and adverse consequences. This can lead to a positive maternal knowledge and attitude towards vaginal delivery [27].

\section{References}

1. American Psychiatric Association (2013) Diagnostic and statistical manual of mental disorders (DSM-5 ${ }^{\circledR}$ ). American Psychiatric Publishing, Washington, DC, USA.

2. National Center for PTSD, US Department of Veterans Affairs (2013) DSM-5 Criteria for PTSD. Brain Line, Washington, DC.

3. Leveno KJ, Hoffman BL, Cunningham FG, Bloom SL (2018) Williams Obstetrics. McGraw-Hill Education, USA.

4. Gamble J, Creedy D, Moyle W, Webster J, McAllister M, et al. (2005) Effectiveness of a counseling intervention after a traumatic childbirth: a randomized controlled trial. Birth 32: 11-19.

5. Soet JE, Brack GA, Dilorio C (2003) Prevalence and predictors of women's experience of psychological trauma during childbirth. Birth 30: $36-46$.

6. Mc Nally RJ (2009) Post traumatic stress disorder. In: Sadock BJ, Kaplan HI, Ruiz P, Sadock VA (eds) Kaplan \& Sadock's comprehensive textbook of psychiatry. Wolters Kluwer Health/Lippincott Williams \& Wilkins, USA, 2650-2660.

7. Domschke K (2012) Patho-genetics of posttraumatic stress disorder. Psychiatr Danub 24: 267-273.
8. Milosavljevic M, Tosevski DL, Soldatovic I, Vukovic O, Miljevic C, et al. (2016) Posttraumatic Stress Disorder after Vaginal Delivery at Primiparous Women. Sci Rep 6: 27554.

9. Rafiei M, Ghare MS, Akbari M, Kiani F, Sayehmiri F, et al. (2018) Prevalence, causes, and complications of cesarean delivery in Iran: a systematic review and meta-analysis. Int J Reprod Biomed 16: 221234.

10. Akbari S, Ahmadi S (2014) Analyzing the effective factors of choosing delivery method of the primiparous pregnant women attending to Khoramabad's Asalian hospital in 2014. Indian J Fundamental Appl Life Sci 4: 656-663.

11. Khatony A, Soroush A, Andayeshgar B, Saedpanah N, Abdi A (2019) Attitude of primiparous women towards their preference for delivery method: a qualitative content analysis. Arch Public Health 77: 38.

12. Jafarzadeh A, Hadavi M, Hasanshahi G, Rezaeian M, Vazirinejad R, et al. (2019) Cesarean or Cesarean Epidemic? Arch Iran Med 22: 663670.

13. Betrán AP, Temmerman M, Kingdon C, Mohiddin A, Opiyo N, et al. (2018) Interventions to reduce unnecessary caesarean sections in healthy women and babies. Lancet 392: 1358-1368.

14. Sahlin M, Carlander-Klint A-K, Hildingsson I, Wiklund I (2013) Firsttime mothers' wish for a planned caesarean section: deeply rooted emotions. Midwifery 29: 447-452.

15. Smarandache A, Kim THM, Bohr Y, Tamim H (2016) Predictors of a negative labour and birth experience based on a national survey of Canadian women. BMC Pregnancy Childbirth 16: 114.

16. Stramrood CAl, Paarlberg KM, Huis In't Veld EM, Berger LWAR, Vingerhoets Ad JJM, et al. (2011) Posttraumatic stress following childbirth in homelike- and hospital settings. J Psychosom Obstet Gynaecol 32: 88-97.

17. Ryding EL, Wijma B, Wijma K (1997) Posttraumatic stress reactions after emergency cesarean section. Acta Obstet Gynecol Scand 76: 856-861.

18. Ryding EL, Wijma K, Wijma B (1998) Psychological impact of emergency cesarean section in comparison with elective cesarean section, instrumental and normal vaginal delivery. J Psychosom Obstet Gynaecol 19: 135-144.

19. Alcorn KL, O'Donovan A, Patrick JC, Creedy D, Devilly GJ (2010) A prospective longitudinal study of the prevalence of post-traumatic stress disorder resulting from childbirth events. Psychol Med 40:1849-1859.

20. Halvorsen L, Nerum H, Øian P, Sørlie T (2008) Is there an association between psychological stress and request for caesarian section? Tidsskr Nor Laegeforen 128: 1388-1391.

21. Nyberg K, Lindberg I, Öhrling K (2010) Midwives' experience of encountering women with posttraumatic stress symptoms after childbirth. Sex Reprod Healthc 1: 55-60.

22. Tham V, Ryding EL, Christensson K (2010) Experience of support among mothers with and without post-traumatic stress symptoms following emergency caesarean section. Sex Reprod Healthc 1: 175180.

23. Söderquist J, Wijma K, Wijma B (2002) Traumatic stress after childbirth: the role of obstetric variables. J Psychosom Obstet Gynaecol 23: 31-39.

24. Olde E, van der Hart O, Kleber R, van Son M (2006) Posttraumatic stress following childbirth: a review. Clin Psychol Rev 26: 1-16. 
25. Zakerihamidi M, Roudsari RL, Khoei EM (2015) Vaginal Delivery vs. Cesarean Section: A Focused Ethnographic Study of Women's Perceptions in The North of Iran. Int J Community Based Nurs Midwifery 3: 39-50.

26. Khamehchian $M$, Adib-Hajbaghery $M$, HeydariKhayat $N$, Rezaei $M$, Sabery M (2020) Primiparous women's experiences of normal vaginal delivery in Iran: a qualitative study. BMC Pregnancy Childbirth 20: 259.

27. Jahromi AS, Rahmanian K, Madani A (2018) Relation of knowledge about cesarean disadvantages and delivery mode selection in women with first pregnancy; south of Iran. J Res Med Dent Sci 6: 550-556. 